\title{
On Results Reporting and Evidentiary Standards: Spotlight on the Global Fund
}

\author{
Rocco Friebel $^{12} \cdot$ Rachel Silverman $^{2} \cdot$ Amanda Glassman $^{2} \cdot$ Kalipso Chalkidou $^{23}$
}

${ }^{1}$ Department of Health Policy, The London School of Economics and Political Science, London, United Kingdom

${ }^{2}$ Center for Global Development, Washington DC, United States of America

${ }^{3}$ School of Public Health, Imperial College London, London, United Kingdom

Since its inception in 2002, the Global Fund to Fight AIDS, Tuberculosis and Malaria (the Global Fund) has disbursed over $\$ 39$ billion across 120 countries. Funding provided by donors, mainly the United States (USA), France, United Kingdom (UK), Germany, and Japan, has undoubtedly affected the lives of millions of people. And as the Global Fund approaches its Sixth replenishment — to be held in France in October 2019 — the recently published results report appears to make a compelling case for further investment. ${ }^{1}$

On the report cover (see figure 1), a headline proclaims "27 Million Lives Saved"over three times the population of Switzerland. Since its publication, this striking figure has been repeated and amplified by advocacy groups ${ }^{2-4}$ and within mainstream news reporting. ${ }^{5-7}$ In the UK, an online application even allows users to calculate the number of lives saved by a specific constituency, drawing a direct line between UK funding for the Global Fund and a proportionate share of lives saved. ${ }^{8}$

At a time when aid scepticism is on the rise and aid budgets are under pressure, the Global Fund is smart to emphasize the health returns on investment from donor contributions. Yet, for these claims to be genuinely helpful to donor governments, which must choose between further investment in the Global Fund and competing uses of scarce financial resources, including for bilateral programmes for HIV, malaria, and tuberculosis, whilst also convincing their increasingly questioning voters and national media, they must accurately, rigorously, and transparently reflect the Global Fund's own contribution to global progress. So, how seriously should donor governments take these numbers? Are funded programmes offering the best possible value for money? How does the Global Fund stack up against other aid investments - many of which will also undergo replenishments within the next two years (see figure 2) $?^{9}$

All the partners...

Examining publicly available documents, ${ }^{1}$ it is our judgment that the Global Fund's claims are not sufficiently supported by available evidence. Most glaring is the question of attribution. In its results reporting and communication materials, the Global Fund

\footnotetext{
${ }^{1}$ Results reports from previous years are no longer available through the Global Fund website, making it difficult to compare this methodology/document to previous iterations.
} 
conflates two ideas about its own nature. First, the Global Fund is presented as a partnership, encompassing every funder, government, non-governmental organisation, implementer and private actor involved in treating or preventing the three diseases in eligible countries. And second, the Global Fund operates as a standalone funding instrument with a roughly $\$ 4$ billion annual budget. The results reporting explicitly takes credit for the accomplishments of the partnership, including bilateral mechanisms like the President's Emergency Plan for AIDS Relief and the President's Malaria Initiative, ${ }^{10,11}$ plus domestic government investments. Yet, the replenishment will advocate for investment in the Global Fund as a funding instrument, attracting resources that could otherwise be channelled elsewhere in the partnership through alternative bilateral or multilateral mechanisms. How can results reporting without direct attribution to the Global Fund as a standalone institution support continued institutional investment? And with domestic resources in particular growing faster than development assistance for some priority conditions such as HIV/AIDS, ${ }^{12}$ attribution across all payers - national, international, public, and private - becomes even more difficult to justify. ${ }^{2}$

... all the interventions...

Moreover, the methodology for calculating lives saved is opaque and problematic. The Global Fund released a one-page "Note on Methodology" within the 2018 results report; the lives saved figure, they claim, is estimated using "the most advanced modelling methods currently available" based on "widely accepted data sources". We are told only that the number of lives saved was calculated as the difference between the actual number of deaths and the expected number of deaths absent any intervention. The counterfactual against which impact is measured is a hypothetical scenario in which all activities for HIV treatment and prevention, malaria control, and tuberculosis control stopped abruptly in 2000. Again, this method is likely to overstate the impact of Global Fund investments per se, explicitly taking credit for all interventions to address the three diseases in its remit - including in large countries like India and South Africa, which have made significant domestic investments in tuberculosis and HIV, respectively. While exact shares will depend on the health outcome under consideration, economic growth alone is estimated to be responsible for about half of maternal and child mortality reduction between 1990 and 2010, ${ }^{13}$ so taking credit for the entirety of mortality reduction is misleading at the least. No further information is provided regarding the model assumptions, methods, limitations, or uncertainty; point estimates are presented without accompanying confidence intervals.

... and all the (right) data

\footnotetext{
${ }^{2}$ The transition to a key performance indicator (KPI) framework based primarily on a "contribution" (vs. attribution) approach was approved by the Global Fund Board in June 2016 for the 2017-2022 strategy period. In Board discussions in 2017, the Secretariat noted that "The Global Fund moved to reporting of full national results under the 2017-2022 KPI framework, to take a more holistic view of performance. The challenge is that national performance reflects collective efforts, not just those of the Global Fund. Information about Global Fund support, compared to other donors, will help with more accurate performance evaluation." 26 The 2018 results report presents the breakdown of funding sources (Global Fund vs. domestic and other donors) for specific highlighted countries and reports the overall contribution of Global Fund financing among all international (but not domestic) financing for each of the three diseases. However, it does not adjust or scale national results vis-à-vis the Global Fund-specific contribution.
} 
In many countries where vital statistic systems are weak or non-existent, different sources of data, which may take the form of published studies, demographic and health surveys, or modelled global health estimates, will often give vastly different results and hence much varying impact estimates. ${ }^{14}$ Therefore, it is unrealistic to assume that mortality estimates by disease and comorbidity are available, up to date, and reliable, (i.e., tuberculosis patients with a positive smear test who die from tuberculosis as per the Global Fund methods note).

The Global Fund's methodology is unclear, unverifiable, and unreproducible. If the modelling exercise is as rigorous as the Global Fund claims - and the data are indeed drawn from appropriate and sufficient sources - its methods and underpinning raw data should be released and subjected to public scrutiny, the cornerstone of a transparent and scientifically rigorous process. Sharing its data repositories and methods, which were presumably sourced and synthesised using public monies, would also qualify as a valuable contribution to the global public good, as it will allow further policy-relevant research that is much needed by funders, development partners, academia, and recipient country governments.

But we would not stop there. The process followed to commission the analyses, including those who carried them out (i.e., especially if external to the Global Fund), also ought to be transparent and shared. Those involved should declare any conflicts of interest and invite a debate on methods, data, and findings, ideally within peer-reviewed literature, to ensure some degree of quality assurance. Such an approach will ultimately strengthen confidence in the Global Fund as an institution when making the case for reinvestment.

\section{Saving the same life twice?}

The Global Fund is not alone in proffering questionable methods to argue for sustained donor investments - and its approach becomes even more problematic when other global health funders generate their own estimates of lives saved using similar methodologies. Recently, an editorial in The Lancet suggested problems with the investment case for the World Health Organization (WHO); the authors highlight a clear disconnect between the WHO's specific activities and budgetary request (i.e., $\$ 14.1$ billion over five years) and grand claims about the potential global impact of Universal Health Coverage (UHC), based on total investment of over \$1 trillion. ${ }^{15}$ Likewise, a recent BMJ analysis claims that a full Global Financing Facility (GFF) replenishment ( $\$ 2.6$ billion) could save up to 34.7 million lives. On a close read, however, it becomes apparent that these projected results encompass the activities of the entire GFF partnership - apparently also including results achieved by Gavi, and the Global Fund, among others. The specific relationship between institutional investment in the GFF and impact of the broader partnership remains unclear. ${ }^{16}$ Each entity claims to save many of the very same lives, making it difficult to distinguish comparative advantage or the investment case for each funding, or technical assistance instrument.

\section{A Question of Evidentiary Standards}

As these and other multilaterals approach donors to refill their coffers, contributor governments must scrutinise these claims and assess whether their taxpayers' money 
has been and will be put to good use. But what should the evidential and governance standards be for making a case for more money and for holding those spending this money accountable? For the health care sector at least, should the standards match those used by the National Institute for Health and Care Excellence in the UK to allocate millions of pounds to the latest cancer drug? ${ }^{17}$ Should they equal academic research standards for publication in peer-reviewed journals? Or, perhaps, should they be consistent with widely accepted principles of good programme evaluation set out by the International Initiative for Impact Evaluation (3ie)? ${ }^{18}$ And with regard to due processes, should the Global Fund - and other multilateral institutions entrusted with large sums of public money - commit to the Open Government principles with respect to the methods and data used to assess project impact? ${ }^{19}$

It is hard to argue that every global health funder, or agency should carry out impact evaluation that would allow for attribution for the entirety of its portfolio; as funders' activities are naturally complementary, efforts to tease out attributable impact of small investments or technical assistance can be an exercise in futility. Yet, modelled results can never fully substitute for empirically verified evaluation, especially when assessing past results. Use of modelling is ubiquitous (and often quite useful); nonetheless, at least some other funders either commission, or can point to rigorous studies that support modelled claims with attributable impact. ${ }^{20-23}$ Countries that receive hundreds of millions of dollars from the Global Fund should also be able to empirically demonstrate that Global Fund investments have indeed led to health improvements, or at the very least attributable supply chain performance or service delivery — without relying wholly on theoretical, modelled results. ${ }^{24}$

\section{Good intentions are not enough...}

With the replenishment forthcoming, we need robust evidence of impact and due process, or we risk empowering the sceptics and compromising the good work of the Global Fund and aid in general. But most importantly, we urge major actors publicly to acknowledge uncertainty in the evidence base underpinning the estimates of their own impact - and to open a robust, frank, and respectful public dialogue about the strength of the evidence. In low- and middle-income countries, uncertainty is unavoidable driven by incomplete death registration data, weak or no evidence of comparative effectiveness of alternative treatments, and a lack of reliable routinely collected billing information to estimate health care resource use, all of which are a given in high-income country settings. Estimates of impact will be more powerful and convincing if they are open to public scrutiny and include clear caveats about this uncertainty, coupled with a call for further investment in evidence and data generation. Perhaps, a donor and development industry-independent (and very public) Aid Fact Checker service could encourage both more moderation in pronouncing impact and more systematic evidence generation to back such pronouncements.

We believe that a more nuanced approach would be more honest and possibly more effective in securing funds for global health relief. And for low- and middle-income countries facing transition from aid dependence ${ }^{25}$ and daunting shortfalls in their domestic health care budgets, showing that evidence-informed advocacy for health can raise billions would perhaps send the most powerful message of all. 


\section{Acknowledgements}

We would like to thank Claire Melamed, Ruth Levine and Owen Barder for useful discussions on incentivising better measurement and reporting of impact. We are also grateful to the three anonymous peer reviewers for their helpful comments and suggestions.

The authors received no funding for this study. RF acting as corresponding author had the final responsibility for the decision to submit for publication.

\section{Author contributions}

$\mathrm{RF}$ and $\mathrm{KC}$ developed the idea, all authors made a significant contribution to the development and write up of this article.

\section{Declaration of interest}

No interests to declare.

\section{Ethics}

This article requires no ethical clearance.

\section{References}

1 The Global Fund. Results Report 2018. 2018 DOI:10.1242/dmm.009662.

2 Ryan K. The results are in: The Global Fund has saved 27 million lives! One. 2018. https://www.one.org/us/2018/09/17/global-fund-saved-27-million-lives/ (accessed Oct 3, 2018).

3 Fight F of the G. 27 Million Lives Saved Through Global Fund-Supported Programming. Friends Glob. Fight. 2018. https://www.theglobalfight.org/27million-lives-saved/ (accessed Oct 3, 2018).

$4 \quad$ Global Funds Advocates Network. Global Fund Results Report. 2018.

$5 \quad$ AFP. 'Global AIDS, TB fight needs more money'. New Vis. 2018. https://www.newvision.co.ug/new_vision/news/1485650/global-aids-tb-fightmoney (accessed Oct 3, 2018).

6 AFP. Global AIDS, TB fight needs more money: health fund. Fr. 24. 2018.

7 Sulcas A. SA shows what is possible in fighting killer diseases. Bus. Day. 2018. https://www.businesslive.co.za/bd/opinion/2018-09-19-sa-shows-whatis-possible-in-fighting-killer-diseases/ (accessed Oct 3, 2018).

8 Lifes Saved Through The Global Fund. STOPAIDS. .

9 Morris S, Lu J, Fisher-Post C. Mapping the Concessional Financing Landscape : Key Data on the Role of Multilateral Institutions and Funds 20192020 Replenishments Overview. 2018; : 1-23. 
10 The United State President's Emergency Plan For AIDS Relief. 15 YEARS OF SAVING LIVES THROUGH AMERICAN GENEROSITY AND

PARTNERSHIPS. https://www.pepfar.gov (accessed Oct 3, 2018).

11 President's Malaria Initiative. Fighting Malaria and Saving Lives. https://www.pmi.gov/about (accessed Oct 3, 2018).

12 Dieleman JL, Haakenstad A, Micah A, et al. Spending on health and HIV/AIDS: domestic health spending and development assistance in 188 countries, 1995-2015. Lancet 2018; 391: 1799-829.

13 Bishai DM, Cohen R, Alfonso YN, Adam T, Kuruvilla S, Schweitzer J. Factors Contributing to Maternal and Child Mortality Reductions in 146 Low- and Middle-Income Countries between 1990 and 2010. PLoS One 2010; 11: 1-13.

14 Boerma T, Victora C, Abouzahr C. Monitoring country progress and achievements by making global predictions: is the tail wagging the dog? Lancet 2018; 392: 607-9.

15 Collier P. The case for investing in WHO. Lancet 2018; 392: 1-4.

16 Chou VB, Bubb-humfryes O, Sanders R, et al. Pushing the envelope through the Global Financing Facility: potential impact of mobilizing additional support to scale-up life-saving interventions for women, children and adolescents in 50 high-burden countries Victoria. BMJ Glob Heal 2018; October.

17 The National Institute for Health and Care Excellence. Improving health and social care through evidence-based guidance. https://www.nice.org.uk (accessed Oct 3, 2018).

18 International Initiative for Impact Evaluation (3ie). Principles for Impact Evaluation. 2015; : 1-2.

19 Partnership OG. Promoting Democracy, Improving Governance, Renewing Trust. https://www.opengovpartnership.org (accessed Oct 3, 2018).

20 Gertler PJ, Giovagnoli P, Martinez S. Rewarding provider performance to enable a healthy start to life: evidence from Argentina's Plan Nacer. 2014 DOI:10.1596/1813-9450-6884.

21 Birdthistle I, Schaffnit SB, Kwaro D, et al. Evaluating the impact of the DREAMS partnership to reduce HIV incidence among adolescent girls and young women in four settings: A study protocol. BMC Public Health 2018; 18: $1-15$.

22 Bendavid E, Holmes C, Bhattacharya J, Miller G. HIV Development Assistance and Adult Mortality in Africa. JAMA 2012; 307: 2060-7.

23 Jakubowski A, Stearns SC, Kruk ME, Angeles G, Thirumurthy H. The US President's Malaria Initiative and under-5 child mortality in sub-Saharan Africa: A difference-in-differences analysis. PLoS Med 2017; 14: 1-20.

24 Glassman A, Fan V, Over M. More Health for the Money. 2013 DOI:10.1016/j.parint.2011.08.011.

25 Silverman R. Projected Health Financing Transitions: Timeline and Magnitude. Washington, DC, 2018.

26 The Global Fund 37th Board Meeting. Kigali https://www.theglobalfund.org/media/6971/bm37_meeting_report_en.pdf. 


\section{Figure legends}

Figure 1: The Global Fund Results Report 2018

Figure 2: Multilateral Concessional Lender Replenishment Timeline Through 2020 